\title{
Guideline for the management of patients with acute coronary syndromes without persistent ECG ST segment elevation
}

\author{
British Cardiac Society Guidelines and Medical Practice Committee, and Royal College of Physicians Clinical \\ Effectiveness and Evaluation Unit
}

\section{Recommendations}

The grading $\mathrm{A}-\mathrm{C}$ for each of the clinical recommendations has been applied according to the definitions used by the Scottish Intercollegiate Guidelines Network ${ }^{1}$ (see appendix I).

\section{Good practice and audit points}

$\checkmark$ Recommended best practice based on the clinical experience of the guideline development group, and appropriate for audit.

\section{Presentation and initial management}

1. Patients presenting with symptoms consistent with an acute coronary syndrome should be referred urgently for further assessment:

- those with prolonged ( $>15$ minutes) cardiac pain at rest should be taken to an acute hospital by emergency ambulance;

- those with worsening angina should be referred to and assessed by a specialist on the day of presentation.

2. All patients should have a 12 lead ECG performed. Patients with persistent ST segment elevation or acute $\mathrm{Q}$ wave myocardial infarction, and those with alternative diagnoses, exit from this guideline and should be managed appropriately.

3. Patients with a suspected acute coronary syndrome should be observed, with repeat 12 lead ECG recording, during symptoms if the opportunity arises. Blood samples for cardiac troponin (troponin $\mathrm{T}$ or $\mathrm{I}$ ) should be taken a minimum of 12 hours after the onset of symptoms. New ischaemic changes on the ECG or elevation of troponin confirm the diagnosis (see table 1 and recommendation 5).

Chairman of the workshop

Nicholas Brooks (Chairman, Guidelines and Medical Practice Committee) Writing group

David Hackett, Nicholas Brooks, Henry Dargie

Specialist reviewers

Kim Fox, diagnosis and risk stratification, Keith Fox, anti-thrombotic treatment, Simon Davies, anti-ischaemic treatment: drugs, David Ramsdale, percutaneous coronary intervention, Ben Bridgewater, surgery

Working group

John Birkhead, David Hackett, Robert Henderson, Richard Hobbs, Malcolm Metcalfe, Ranjit More, Michael Pearson, Henry Purcell, Howard Swanton (President BCS), Robert West, Robert Wilcox, Richard Wray, Ms Lynne Walker (Audit Co-ordinator, BCS)

This guideline was developed at a workshop held on 7 October 1999 at the British Cardiac Society. The audit office of the British Cardiac Society administered the workshop for the preparation of this guideline, and has received funding from the National Institute for Clinical Excellence. The views expressed are those of the authors and not necessarily those of NICE.
4. If at least $\mathbf{1 2}$ hours after the onset of symptoms of a suspected acute coronary syndrome:

- the symptoms have not recurred;

- the cardiac troponin is normal;

- the ECG remains normal (or unchanged compared with a recording from before the current presentation);

- and the cardiac enzymes are not raised;

the patient can be mobilised and discharged. Risk assessment with stress testing should be performed unless contraindicated, preferably before discharge from hospital.

\section{$\checkmark A$}

5. Patients with a confirmed acute coronary syndrome should be admitted to a cardiac care unit or high dependency unit with continuous ECG rhythm monitoring. If symptoms recur the 12 lead ECG should be repeated.

6. Confirmed acute coronary syndrome. Patients who have had ischaemic ECG changes, or cardiac troponin release or raised CK-MB enzyme demonstrated at any time during admission, have a confirmed acute coronary syndrome. When free from symptoms and ischaemic ECG changes for $>48$ hours, and any intravenous treatments and heparin have been stopped for $>24$ hours, risk assessment with stress testing should be performed, unless contraindicated; stress testing for risk assessment is unnecessary if the patient is already in a high risk category for which coronary angiography is indicated.

Risk assessment and referral for coronary angiography

7. Patients with unstable angina or non-Q wave myocardial infarction should have their cardiac prognosis assessed by estimation of their risk of death or further cardiac events. In patients whose symptoms and condition have become stable after initial treatment, this assessment should include stress testing. Treatment should be directed at reducing their risk.

8. Referral for coronary angiography. Patients with recurrent or refractory angina should be referred for coronary angiography with a view to myocardial revascularisation for relief of symptoms; these patients are also in a category at high risk of further cardiac events. 
9. Those patients with unstable angina or non-Q wave myocardial infarction whose condition has stabilised, but who are at high risk of death or further cardiac events, should be referred for coronary angiography.

10. Referral for coronary angiography in medically stabilised patients: risk stratification using the results of troponin and stress tests (see table 2):

A. Low risk: If the cardiac troponin result is negative or low (troponin $\mathrm{T}<0.01 \mu \mathrm{g} / 1$ or troponin I equivalent), and the stress test result indicates a low risk category, the patient can be discharged; if free from cardiac symptoms, no further cardiac interventions are necessary. Subsequent outpatient review is appropriate for further investigations to confirm or exclude a coronary diagnosis, and adjustment or cessation of drug treatment.

B. Intermediate risk: Patients without high risk features, such as evidence of impaired left ventricular function, or haemodynamic abnormalities or arrhythmia during the acute phase, and who have either:

- a normal cardiac troponin result (troponin $\mathrm{T}<0.01 \mu \mathrm{g} / \mathrm{l}$, or troponin I equivalent) and with a stress test indicating intermediate risk; or

- moderately elevated cardiac troponin (troponin $\mathrm{T} 0.01 \mu \mathrm{g} / 1$ to $0.1 \mu \mathrm{g} / 1$, or troponin I equivalent) and with a stress test result indicating a low risk category;

are at an intermediate level of risk. Many cardiologists perform coronary angiography on patients in these categories of intermediate risk, and this practice has been recommended; but coronary angiography cannot be considered mandatory in the current absence of clear evidence that routine investigation of such patients results in an improved outcome.

C. High risk: If the maximal cardiac troponin result is high (troponin $\mathrm{T}>0.1 \mu \mathrm{g} / \mathrm{l}$, or troponin $\mathrm{I}$ equivalent), or the stress test result indicates a high risk category, coronary angiography should be arranged, unless contraindicated, and performed urgently, before discharge from hospital. Those with acute ischaemia associated with hypotension, arrhythmia, or heart failure, are also in a high risk category and should be referred for coronary angiography.

D. Patients unable to exercise: If the patient is unable to perform an exercise ECG, an alternative non-exercise (pharmacological) stress test, such as a stress echocardiograph or isotope myocardial stress perfusion study, should be arranged unless contraindicated; coronary angiography should be undertaken according to the risk category determined, if indicated as described above. If no stress test can be performed, and the maximal cardiac troponin result is intermediate or high, coronary angiography should be arranged, unless contraindicated. If no stress test can be performed, and if the troponin result is low and there are no further symptoms or ECG changes, the patient may be able to be discharged and reviewed in the outpatient clinic.
Antithrombotic treatment

11. All patients with a confirmed acute coronary syndrome should be given aspirin, unless contraindicated, as soon as the diagnosis is made; low dose aspirin once daily should be continued subsequently, unless contraindicated.

12. Low molecular weight heparin should be given for at least two days, and for up to eight days or longer in cases of recurrent ischaemia or where myocardial revascularisation is delayed or contraindicated.

\section{Medical anti-ischaemic treatment}

13. To reduce their risk of infarction, all patients with a confirmed acute coronary syndrome should be treated with a $\boldsymbol{\beta}$ blocker without intrinsic sympathomimetic activity, and where there is no contraindication. Where there is a contraindication to the use of $\beta$ blockers, $\mathbf{a}$ heart rate slowing calcium channel antagonist should be given to all patients with a confirmed acute coronary syndrome with no evidence of heart failure or left ventricular dysfunction to reduce their risk. Nitrates should be given to relieve pain or ischaemia in patients with an acute coronary syndrome; if further symptoms or ischaemia occurs, a calcium channel antagonist can be added to the $\beta$ blocker. A potassium channel opener should be given in addition to nitrates and $\beta$ blockers (or calcium channel antagonists) if there are recurrent symptoms or ischaemia.

Management of cases at high risk

14. Treatment with an intravenous small molecule platelet glycoprotein IIb/IIIa inhibitor for up to 96 hours should be given to patients with an acute coronary syndrome at high risk of an adverse outcome. An intravenous platelet glycoprotein IIb/IIIa inhibitor should be administered to patients with an acute coronary syndrome with elevated cardiac troponin who are scheduled to undergo percutaneous coronary intervention using unfractionated heparin. This should be commenced before intervention.

15. Recurrent or refractory acute coronary syndromes. Patients with a recurrent acute coronary syndrome (recurrent symptoms or ischaemic ECG changes despite aspirin and anti-ischaemic medical treatment), especially those who have cardiac troponin release demonstrated at any time during admission, should be referred, unless contraindicated, directly for inpatient coronary angiography and myocardial revascularisation. An intravenous platelet glycoprotein IIb/ IIIa inhibitor should be administered, and low molecular weight heparin continued until angiography. Patients with a refractory acute coronary syndrome (ischaemic ECG ST segment changes despite aspirin, heparin and anti-ischaemic medical treatment) should have an intravenous platelet glycoprotein IIb/IIIa inhibitor administered, and be referred, unless contraindicated, directly for urgent inpatient coronary angiography and myocardial revascularisation. 


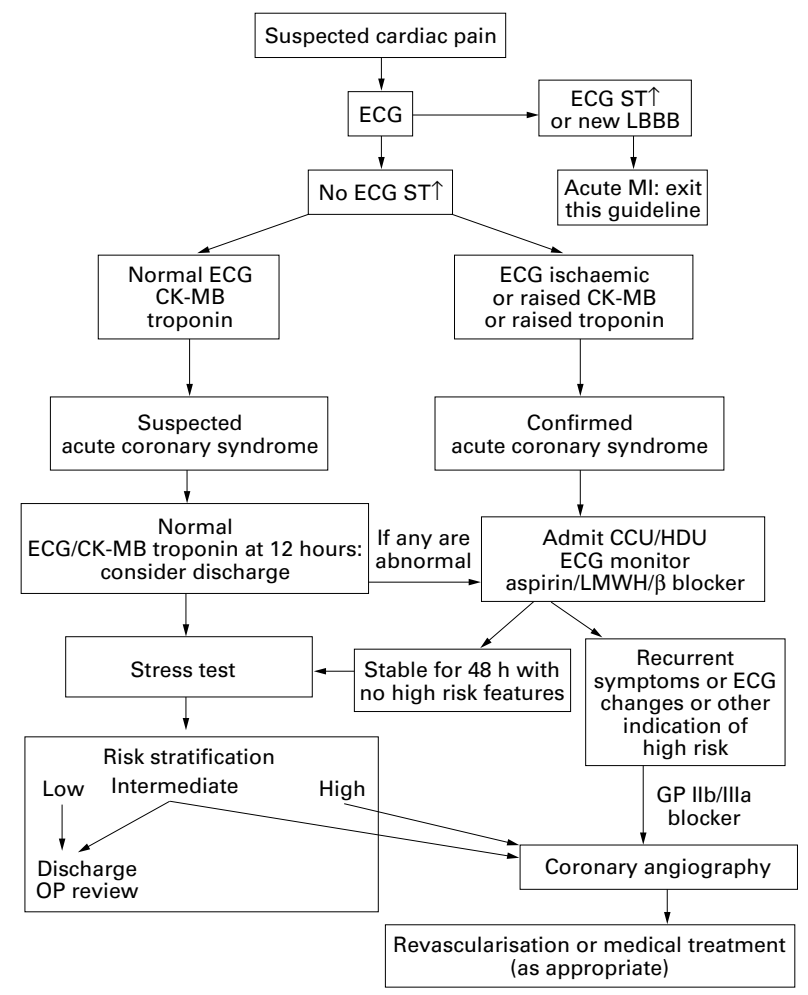

Figure 1 Summary flow chart for management of patients with suspected acute coronary syndromes without ECG ST segment elevation.

Treatment with cardiac surgery

16. In patients with unstable angina or non-Q wave myocardial infarction in whom coronary artery bypass graft surgery is indicated, surgery should be delayed until medical stabilisation, if this can easily be achieved.

17. Patients with unstable angina and left main stem stenosis or equivalent with evidence of myocardial ischaemia, or with triple vessel disease and impaired left ventricular function, should have coronary artery bypass graft surgery performed, unless the risk or prognosis from comorbidity would result in an unacceptably increased operative risk.

18. Patients previously referred for and awaiting coronary artery bypass graft surgery who develop an unstable coronary syndrome should be given priority on waiting lists over those patients with stable angina, and have their CABG surgery expedited.

General management

19. It is important to treat hypertension and heart failure in patients with acute coronary syndromes.

20. Patients with confirmed unstable angina or non-Q wave myocardial infarction should have advice on and management of their risk factors.

Figure 1 shows a summary flow chart for management of patients with suspected acute coronary syndromes without ECG ST segment elevation.
Guideline for the management of patients with acute coronary syndromes without ECG ST segment elevation

1. Introduction

1.1 Patients presenting with acute coronary syndromes, but without persistent ECG ST segment elevation, have unstable angina or non- $Q$ wave myocardial infarction. They are estimated to account for at least 120000 admissions to UK hospitals each year. Treatment can alleviate recurrent symptoms and ischaemia and improve prognosis, but clinical management has been reported to vary widely. ${ }^{2}$ The frequency of the condition, its potential for complications, the cost to the community and inconsistent management provide the justification for the production of this guideline.

\section{Methods}

2.1 The guideline development group. This guideline was developed by a working group nominated by the Guidelines and Medical Practice Committee of the British Cardiac Society in collaboration with the Clinical Effectiveness and Evaluation Unit of the Royal College of Physicians (London). Members of the group represented interests from public health, primary care, district general hospitals (both cardiologists and general physicians) and tertiary centres, and advice was obtained from representatives of patient groups (appendix II). The guideline reflects the consensus of the group derived from presentations by five specialist reviewers on the following subjects: diagnosis and risk stratification, antithrombotic and anti-ischaemic treatment with drugs, angioplasty, and surgery.

2.2 Literature search. The specialist reviewers carried out a review of their subject based on their own knowledge and an exhaustive search of the literature. Electronic searches of Medline and the Cochrane database, using the key words acute coronary syndromes, unstable angina or non-Q wave myocardial infarction, yielded over 5000 papers in peer review journals since 1986; and associated drug treatment, aspirin, heparin, low molecular weight heparin, glycoprotein IIb/IIIa antagonists, angioplasty, coronary artery bypass graft surgery yielded over 3000 papers. We have not attempted to perform a systematic review of the quality of individual studies included in published meta-analyses or systematic reviews. This guideline and the recommendations are based on evidence reviewed from the medical literature up to December 1999.

\subsection{Strength of evidence and grades of recommenda-} tions. The strength of evidence and the recommendations drawn from it were classified according to the definitions used by the Scottish Intercollegiate Guidelines Network, ${ }^{1}$ derived from the US Agency for Health Care Policy and Research ${ }^{3}$ (see appendix I).

2.4 Scope of this guideline. The guideline is intended to improve the care of patients and is primarily for hospital doctors involved in the reception and management of patients presenting with a suspected acute coronary syndrome. Patients found to have persistent ECG ST segment elevation confirming an acute (potential Q wave) myocardial infarction, and those with a non-cardiac diagnosis, are excluded from this guideline when one of these diagnoses is established. The guideline is concerned with the initial diagnosis of 
acute coronary syndromes, assessment of patients and confirmation of the diagnosis, risk stratification, medical treatment, indications for coronary angiography, and the role of coronary angioplasty and surgery. It reflects the consensus of opinion of the working group, derived from the evidence, and is applicable to the majority of patients. Recommendations for investigations and treatments are made only where they can be justified on the basis of evidence of clinical benefit. The guideline does not preclude the use of alternative approaches in individual patients, and should not be used to override clinical judgement. It is accepted that resources may limit the use of expensive treatments, but this guideline has not attempted a costeffectiveness analysis. It is recommended that this guideline should be used as a template to be adapted for local use.

2.5 Date for review. Rapid advances in the management of patients with acute coronary syndromes have occurred in recent years, and major trials of drug and interventional treatment are expected to report soon. This guideline should be reviewed by January 2002 .

\section{Causes of acute coronary syndromes}

3.1 Acute coronary syndromes without ECG ST segment elevation result from the abrupt, total or subtotal, transient and typically recurrent obstruction of a coronary artery. ${ }^{4-7}$ They are caused, in most cases, by rupture or erosion of the cap of an atheromatous plaque with consequent platelet activation leading to obstruction of the vessel by various contributions from thrombus, vasoconstriction or spasm. Spontaneous lysis or fragmentation of the thrombus, or the relief of spasm, allows the ischaemia to resolve, but distal embolism may result in myocardial necrosis. Persistence of an occlusive thrombus leads, in the absence of effective collateral blood supply, to a fully developed infarction typically with Q waves on the ECG. Traditionally the diagnosis of unstable angina has required the exclusion of infarction. The use of sensitive markers of myocardial necrosis has shown that a continuum exists from myocardial ischaemia to non- $Q$ wave infarction; thus, it is logical and practical to consider the diagnosis, investigation, and management of this continuum together as a single entity of acute coronary syndromes without ECG ST segment elevation. The management of acute coronary syndromes without ECG ST segment elevation is distinct from that of acute myocardial infarction with persistent ECG ST segment elevation.

\section{Natural history}

4.1 Symptoms consistent with a diagnosis of an acute coronary syndrome precede about $50 \%$ of acute myocardial infarctions and sudden cardiac deaths. ${ }^{8}$ The risk of an adverse outcome is particularly high early after the onset of symptoms; in an historic cohort of medically treated patients, this increased risk has been shown to decline to a level approaching that of stable coronary artery disease by two months later (see table 5 and figure 2 in reference 3$).^{3}$ In patients with a diagnosis of unstable angina or non-Q wave infarction, the overall risk of death or (further) infarction is about $10 \%$ during the first 30 days, and an additional $35-50 \%$ will experience recurrent ischaemia despite medical treatment. ${ }^{29-12}$

Evidence level IIb
Table 1 Initial diagnostic assessment: patients presenting with symptoms of a suspected acute coronary syndrome

\begin{tabular}{|c|c|c|}
\hline Initial laboratory assessment & Clinical diagnosis & Diagnostic category \\
\hline $\begin{array}{l}\text { ECG shows persistent ST } \\
\text { segment elevation }\end{array}$ & $\begin{array}{l}\text { ST segment elevation } \\
\text { myocardial infarction }\end{array}$ & Exit this guideline \\
\hline $\begin{array}{l}\text { ECG normal or ischaemic } \\
\text { changes (no persistent ECG } \\
\text { ST-segment elevation) } \\
\text { Raised CK-MB enzyme } \\
\text { (more than twice the upper } \\
\text { limit of the reference range) } \\
\text { and cardiac troponin } \\
\text { positive }\end{array}$ & $\begin{array}{l}\text { Non- } Q \text { wave } \\
\text { myocardial infarction }\end{array}$ & $\begin{array}{l}\text { Confirmed acute } \\
\text { coronary } \\
\text { syndrome }\end{array}$ \\
\hline $\begin{array}{l}\text { ECG shows ischaemic } \\
\text { changes (no persistent ECG } \\
\text { ST-segment elevation) and/or } \\
\text { cardiac troponin positive } \\
\text { CK-MB enzyme not raised }\end{array}$ & $\begin{array}{l}\text { Confirmed unstable } \\
\text { angina }\end{array}$ & $\begin{array}{l}\text { Confirmed acute } \\
\text { coronary } \\
\text { syndrome }\end{array}$ \\
\hline $\begin{array}{l}\text { ECG normal } \\
\text { Cardiac troponin normal } \\
\text { CK-MB enzyme not raised }\end{array}$ & $\begin{array}{l}\text { Suspected unstable } \\
\text { angina }\end{array}$ & $\begin{array}{l}\text { Unconfirmed } \\
\text { acute coronary } \\
\text { syndrome }\end{array}$ \\
\hline
\end{tabular}

\section{Definition}

5.1 Acute coronary syndromes without ECG ST segment elevation, comprising unstable angina and non-Q wave myocardial infarction, excludes, by definition, persistent ECG ST segment elevation and acute $\mathrm{Q}$ wave myocardial infarction. The most frequently cited classification of the time course and mode of presentation of patients with unstable angina has been that proposed by Braunwald. ${ }^{13}$

5.2 Diagnosis is based on the clinical history, the admission or subsequent 12 lead ECG, and cardiac enzymes or other markers in plasma (table 1$).{ }^{3}$ Various imaging tests can confirm myocardial perfusion or wall motion abnormalities.

5.3 Patients usually present with one of the following patterns of symptoms ${ }^{3}$ :

- new onset (less than two months) of severe angina (CCSC class III or IV);

- abrupt worsening of previous angina, with symptoms becoming more frequent, more severe, or more prolonged and less responsive to nitroglycerine;

- prolonged (> 15 minutes) angina occurring at rest.

5.4 The ECG may show ${ }^{3}$ :

- ST segment depression;

- transient ST segment elevation that resolves spontaneously or after nitroglycerine;

- T wave inversion;

- evidence of previous myocardial infarction;

- left bundle branch block;

- minor non-specific changes;

- or can be normal;

but should not show persistent acute ST segment elevation.

5.5 Continuous ECG ST segment monitoring provides additional information on diagnosis and risk assessment. $^{1415}$

Evidence level III

5.6 Conventional cardiac enzymes (CK, CK-MB, AST, $\mathrm{LDH}$ ) may be normal or elevated. Detection in the blood of elevated troponin I or T concentrations is highly specific for myocardial damage and identifies patients at high risk for complications. ${ }^{16-20}$ Troponin $\mathrm{T}$ $>0.1 \mu \mathrm{g} / 1$ or troponin $\mathrm{I}>0.4 \mu \mathrm{g} / 1$ are independent markers associated with an increased risk of early 
death in patients with an acute coronary syndrome without ECG ST segment elevation; and the higher the cardiac troponin concentration the greater the risk of death within 30-42 days of presentation. ${ }^{2122}$ Normal or undetectable troponin concentrations more than 12 hours after the onset of symptoms identifies patients with a low risk of early complications. ${ }^{18-20}$

Evidence level IIa

\section{Risk assessment}

6.1 The assessment of risk should be a continuous process. Patients in whom the diagnosis of unstable angina or non- $Q$ wave myocardial infarction is confirmed are at heightened risk for an early coronary event; but all patients with coronary artery disease, including those in whom the diagnosis of an acute coronary syndrome is discounted, remain at some risk throughout their lives.

6.2 For those with an acute coronary syndrome the risk of an early adverse outcome is increased in the following circumstances:

- age $>65$ years old ${ }^{23}$;

- comorbidity, especially diabetes ${ }^{24}$;

- prolonged (> 15 minutes) cardiac pain at rest $^{25}$;

- ischaemic ECG ST segment depression on admission or during symptoms ${ }^{26-29}$;

- ECG $\mathrm{T}$ wave inversion (associated with a risk intermediate between that associated with ST segment depression and a normal ECG) ${ }^{26}{ }^{29}$;

- evidence of impairment of left ventricular function (either pre-existing or during myocardial ischaemia) ${ }^{3}$;

- cardiac troponin release positive $\mathrm{e}^{18-20}$;

- elevated C-reactive protein (determined by specific high sensitivity assay). ${ }^{30} 31$

Evidence level IIb

6.3 It is important to manage hypertension and heart failure in the acute phase of acute coronary syndromes, as treatment can diminish wall stress and myocardial ischaemia, and can help to stabilise the patient. $^{29}$

\section{Evidence level Ib}

6.4 Studies of troponin $\mathrm{T}$ compared with troponin I indicate that the two markers are equally sensitive and specific, and have similar prognostic significance, and support their role in risk stratification. ${ }^{32}$

Evidence level Ia

6.5 Low risk categories: A normal cardiac troponin at 12 hours after the onset of symptoms can identify a group of people at low risk of immediate cardiac events; furthermore these patients who also have a normal ECG and normal cardiac enzymes (CK-MB) do not need admission to a coronary care or high dependency unit. ${ }^{20}{ }^{33}$ Chest pain assessment units for patients at low cardiac risk have been shown to provide effective care and possible cost savings compared with usual hospital care in the USA ${ }^{34-38}$ and in the UK. ${ }^{39} 40$ It would be appropriate to evaluate chest pain assessment units in the UK, for the management of patients presenting with suspected cardiac pain but thought to be at low cardiac risk, and in whom the aim would be to exclude an acute coronary syndrome. ${ }^{41}$

Evidence level IIb

6.6 One study has shown that in patients with suspected unstable angina, when both CK-MB $\mathrm{MBss}_{\text {ma }}$ and troponin I remain normal at 0,4 , and 8 hours after presentation, there is a favourable early (up to 24 hours) prognosis; the negative predictive value was $99 \%$ in excluding myocardial infarction or need for urgent myocardial revascularisation. ${ }^{33}$ Another study has shown that in patients presenting with suspected unstable angina and non-diagnostic ECGs, a normal resting myocardial isotope perfusion study is associated with a low risk. ${ }^{42}{ }^{43}$ Such patients do not need admission to a coronary care unit.

\section{Evidence level IIb}

6.7 Recurrent and refractory acute coronary syndromes: definitions

- Recurrent acute coronary syndrome is defined as a recurrence of symptoms or ischaemic ECG changes despite treatment with aspirin and medical anti-ischaemic agents within two months of the diagnosis of a confirmed acute coronary syndrome.

- Refractory acute coronary syndrome is defined as a recurrence of symptoms and ischaemic ECG ST segment changes despite treatment with aspirin, heparin, and medical anti-ischaemic agents.

6.8 Risk stratification: After initial assessment and treatment, increased risk is indicated by:

- raised cardiac troponin concentration ${ }^{32}$;

- recurrent ischaemic symptoms ${ }^{25}$;

- recurrent ischaemic ST segment changes (with or without symptoms $)^{1415}$;

- adverse exercise ECG or other stress test result ${ }^{44-48}$;

- impaired left ventricular function. ${ }^{349}$

Patients with the worst prognosis are those with continuing or recurrent symptoms and ischaemic ECG ST segment changes despite anti-ischaemic medical treatment and aspirin and heparin (= refractory ischaemia); and particularly if occurring soon after a myocardial infarction or with preexisting evidence of coronary heart disease (Braunwald class IIIB or IIIC). ${ }^{50}$

Evidence level III

6.9 In patients whose spontaneous symptoms resolve, stress testing provides valuable risk stratification (table 2). Increased risk is associated with:

- poor exercise tolerance (less than 3 minutes or stage II on the standard Bruce protocol or equivalent $)^{44}$;

- ischaemic ECG ST segment changes ${ }^{44}$;

- an abnormal isotope stress perfusion or stress echocardiographic scan. ${ }^{42} 4345-48$

Stress echocardiography has been reported to be more sensitive and specific in assessment of risk than exercise ECG testing in patients with unstable angina. ${ }^{24} 51$

Evidence level IIb

6.10 Stabilised acute coronary syndrome: Patients with unstable angina or non-Q wave myocardial infarction whose condition has become stable with initial treatment, and who have non-invasive investigations which indicate a low risk category, have no evidence of benefit to their outcome from routine invasive investigations or interventions. ${ }^{52}$

Evidence level Ib

7. Antithrombotic treatment for confirmed acute coronary syndromes

7.1 Aspirin reduces the risk of cardiac death and non-fatal myocardial infarction by about $50 \%$ in unstable coronary syndromes. ${ }^{53}$

Evidence level Ia 
Table 2 Example of risk stratification with troponin and exercise ECG results

\begin{tabular}{|c|c|c|c|c|}
\hline \multicolumn{2}{|l|}{ Exercise ECG } & \multicolumn{3}{|c|}{ Risk of cardiac death or MI at 5 months ${ }^{44}$} \\
\hline Result & $\begin{array}{l}\text { Exercise ECG risk } \\
\text { category }^{44}\end{array}$ & $\begin{array}{l}\text { Troponin T } \\
\geqslant 0.2 \mu \mathrm{g} / \mathrm{l}\end{array}$ & $\begin{array}{l}\text { Troponin T } \\
0.2-0.06 \mu \mathrm{g} / \mathrm{l}\end{array}$ & $\begin{array}{l}\text { Troponin T } \\
<0.06 \mu \mathrm{g} / \mathrm{l}\end{array}$ \\
\hline Both low maximal workload achieved, and ST $\downarrow \geqslant 0.1 \mathrm{mV}$ in $\geqslant 3$ leads & High risk & $34 \%$ & $19 \%$ & $22 \%$ \\
\hline Either a low maximal workload achieved or ST $\downarrow \geqslant 0.1 \mathrm{mV}$ in $\geqslant 3$ leads & Intermediate risk & $16 \%$ & $9 \%$ & $7 \%$ \\
\hline Both a low maximal workload exceeded, and without $S T \downarrow \geqslant 0.1 \mathrm{mV}$ in $\geqslant 3$ leads & Low risk & $5 \%$ & $7 \%$ & $1 \%$ \\
\hline Unable to perform exercise ECG & & $27 \%$ & $16 \%$ & $3 \%$ \\
\hline
\end{tabular}

Note: The confidence intervals for the quoted risk of cardiac death or myocardial infarction will be wide and may overlap for many of these categories. Furthermore, the results of troponins and exercise ECG tests are continuous rather than categorical variables, and should be interpreted accordingly. Thus these categories should be interpreted as indicating the general degree of cardiac risk, rather than a precise figure.

Definition: Low maximal workload achieved during exercise ECG. The definition of low maximal workload achieved was that below the 33rd centile of the distribution of the patients studied. ${ }^{44}$ These low workloads achieved on a bicycle ergometer were $90 \mathrm{~W}$ for men and $70 \mathrm{~W}$ for women. The approximate equivalents using the standard Bruce protocol on a treadmill would be less than stage II ( $\leqslant 3.0$ minutes).

Heavy shading $=$ high risk; light shading $=$ intermediate risk; no shading $=$ low risk .

7.2 Unfractionated heparin without aspirin is more effective than placebo in reducing the risk of complications in patients with unstable angina or non-Q wave myocardial infarction..$^{54}$ Unfractionated heparin combined with aspirin may be more effective than aspirin alone ${ }^{56}$; low molecular weight heparin combined with aspirin is more effective than aspirin alone. ${ }^{11}$ Studies of low molecular weight heparin combined with aspirin have shown either equivalence or superiority compared with unfractionated heparin with aspirin. ${ }^{12}$ 57-60 One study has shown a benefit in reduction of death, myocardial infarction and revascularisation with long term use of low molecular weight heparin for up to 30 days, and up to 60 days, although the benefit was not significant by 90 days or at six months. ${ }^{61}$ Meta-analysis has shown no clear difference in efficacy or safety between low molecular weight and unfractionated heparin when used for up to seven days in patients with acute coronary syndromes ${ }^{62}$; longer term use (more than seven days) of low molecular weight heparin is associated with an increased risk of major bleeding. ${ }^{62}$ In general, heparin is of benefit when used for at least two days, and for up to eight days if there is continuing ischaemia or high clinical risk, and longer if myocardial revascularisation is delayed or contraindicated. ${ }^{12}$ 57-60

Evidence level Ib

7.3 Subcutaneous low molecular weight heparin is easier to administer than intravenous unfractionated heparin, has more consistent antithrombin effects, has no need for routine anticoagulant monitoring, and has a similar safety profile.

\section{Evidence level III}

7.4 Platelet glycoprotein IIb/IIIa receptor blockers: Intravenous treatment with a platelet glycoprotein IIb/ IIIa receptor blocker reduces the risk of complications in patients with unstable angina or non- $Q$ wave myocardial infarction treated with aspirin and unfractionated heparin. ${ }^{63}$ The greatest benefit, in terms of the number of patients needed to treat to avoid one complication, is in those at high risk such as cardiac troponin release positive, ischaemic ECG ST segment depression, refractory unstable angina, or undergoing invasive percutaneous coronary intervention. ${ }^{64-68}$ Meta-analyses show that the principal effect is a reduction in the risk of myocardial infarction, but there is also evidence of reduction in mortality as well. ${ }^{63} 69$ The three currently available agents are abciximab, tirofiban, and eptifibatide. ${ }^{70}{ }^{71}$ Abciximab is a monoclonal antibody, whereas tirofiban and eptifibatide are small molecules and thus more suitable for repeated intravenous administration. All have been shown to be effective, but no direct comparisons between agents have been made. Currently, trials of efficacy of platelet glycoprotein IIb/IIIa receptor blockers on patients also receiving low molecular weight heparin have not been reported. Platelet glycoprotein IIb/IIIa receptor blockers are not indicated for unselected use in all patients with acute coronary syndromes; such agents should be used in those at high risk of an adverse event, or undergoing percutaneous coronary intervention.

Evidence level Ia

7.5 Thrombolytic treatment has not been shown to be of benefit in patients with acute coronary syndromes without ECG ST segment elevation (except for those with suspected acute myocardial infarction and left bundle branch block). ${ }^{10} 72-75$

Evidence level Ia

8. Medical anti-ischaemic treatment

8.1 Medical treatment for relief of symptoms: Medical treatment can relieve symptoms and myocardial ischaemia in patients with acute coronary syndromes.

8.2 In several observational studies of patients with unstable angina, intravenous administration of nitrates has been shown to relieve chest pain and ischaemia. ${ }^{76-81}$ There is no evidence that administration by intravenous infusion is more efficacious than equipotent doses of long acting nitrates given by other routes ${ }^{82-84}$; but titration of dose may be quicker and easier to manage with intravenous administration.

Evidence level III

8.3 $\beta$ Blockers can relieve pain and ischaemia in patients with acute coronary syndromes. ${ }^{85-87}$ Calcium channel antagonists can be added to a $\beta$ blocker, and the combination of both seems better than either alone in relieving ischaemia. ${ }^{85-89}$

Evidence levels Ib-IIa

8.4 Nicorandil administered in addition to $\beta$ blockers or calcium channel antagonists, or both, reduces the frequency of angina, ischaemia, and arrhythmias in patients with unstable angina. ${ }^{90}$

Evidence level Ib

8.5 Medical treatment for prognostic benefit: A meta-analysis of four studies of 4700 patients with unstable angina demonstrated a $13 \%$ reduction in the risk of developing myocardial infarction among patients treated with $\beta$ blockers. ${ }^{91}$ There is some evidence that diltiazem is associated with a reduction in reinfarction, not mortality, after non- $Q$ wave 
myocardial infarction, but only in those patients with preserved left ventricular function ${ }^{92-94}$; similar findings have been reported with verapamil. ${ }^{95}$ In subgroup analysis of another study, verapamil given after myocardial infarction to those patients without heart failure was associated with a lower mortality. ${ }^{96}$ There is no evidence that nitrate drugs, the dihydropyridine group of calcium channel antagonists, or potassium channel openers are beneficial in reducing mortality or the risk of myocardial infarction in patients with unstable angina.

Evidence levels Ia-Ib

9. Myocardial revascularisation

9.1 Myocardial revascularisation, with coronary artery bypass graft surgery or angioplasty, is effective in relieving angina in patients who continue to experience recurrent ischaemia despite medical treatment. $^{.7-99}$

Evidence level Ia

9.2 The two trials comparing surgical with medical treatment carried out in the 1970 s showed no overall reduction in mortality or rates of infarction in the surgical group. ${ }^{100-104}$ Both trials demonstrated improved survival for patients with obstructive left main stem disease, or with obstructive three vessel coronary artery disease associated with moderately impaired left ventricular function; these results are consistent with the meta-analysis of the surgical trials performed in patients with chronic stable coronary artery disease. ${ }^{105}$ There have been improvements in surgical and anaesthetic techniques since these trials were conducted; and both trials were carried out before the introduction of currently used treatments with aspirin, low molecular weight heparin, platelet glycoprotein IIb/ IIIa receptor antagonists, or the statin lipid lowering agents.

Evidence level Ib

9.3 Myocardial revascularisation: There is no robust evidence favouring a strategy of routine early myocardial revascularisation, with angioplasty or CABG surgery according to the angiographic findings, which can be derived from the more recent trials. In the TIMI IIIB study the results of intervention and medical treatment were comparable in terms of mortality and non-fatal infarction, while in the VANQUISH study of men with non-Q-wave myocardial infarction there was a high interventional mortality rate of $11 \% .^{106}{ }^{107}$ These findings are also consistent with the results of the MATE study. ${ }^{108} \mathrm{~A}$ meta-analysis shows that there is no clear superiority of early invasive management. ${ }^{109}$ In contrast, patients with acute coronary syndromes treated by myocardial revascularisation (mainly angioplasty) after an average of four to seven days from the onset of symptoms in FRISC II had a lower mortality and incidence of infarction at six months compared with those managed with intensive medical treatment. ${ }^{110}$ Analysis of the GUSTO IIb study has found that mortality was lower among patients treated with an invasive strategy, after adjustment for baseline differences. ${ }^{111}$

Evidence level Ib

9.4 These randomised studies of routine coronary angiography and myocardial revascularisation in patients with unstable angina or non-Q wave myocardial infarction quoted in section 9.3 have been criticised. ${ }^{112}$ Highly selected groups of patients were investigated. Overall outcomes and risks of procedures differed between older and more recent studies. Coronary angioplasty and other percutaneous techniques are constantly evolving, and these randomised studies were performed before the widespread use of coronary stents or platelet glycoprotein IIb/IIIa antagonists. Whether routine coronary angiography and myocardial revascularisation, using mainly angioplasty with current techniques, improves the outcome of all patients presenting with acute coronary syndromes remains unresolved. With doubt over the benefit from routine revascularisation, there is also uncertainty about the precise threshold of risk assessed in asymptomatic patients above which coronary angiography or intervention is indicated. The frequency of use of coronary angiography and revascularisation procedures varies widely between and often within countries. ${ }^{2}$ At present, it is appropriate to direct invasive investigations and interventions to those patients with recurrent symptoms or ischaemia, or who are otherwise at high risk. ${ }^{49} 52$

Evidence level IV

9.5 Recurrent admissions: Further investigations to confirm or refute myocardial ischaemia or coronary artery disease are appropriate in patients who have had recurrent admissions with suspected cardiac pain but unconfirmed acute coronary syndromes and negative or inconclusive exercise tests. These further investigations could include an isotope stress perfusion or stress echocardiographic scan, or coronary angiography, or both. ${ }^{114}$

Evidence level IV

9.6 When coronary artery bypass graft surgery is performed urgently in patients with unstable angina or non-Q wave myocardial infarction, a greater risk of complications exists than in patients with stable coronary artery disease. ${ }^{115-119}$

Evidence level IIb

9.7 A number of studies (FRISC II and TIMI IIIB) have suggested that coronary artery bypass graft surgery carried out urgently for unstable angina can be performed with low mortality ${ }^{106}{ }^{110}$; however, this is not supported by data from large registries in both the UK and USA. ${ }^{100} 104105115116120-122$ The indications from the two randomised studies of an overall benefit from an early invasive approach would not be expected in general clinical practice unless surgery for unstable angina can be performed with an operative mortality at a lower level than is currently being achieved.

Evidence level IIa

9.8 Myocardial revascularisation with cardiac surgery: For patients with unstable angina and left main stem stenosis or equivalent with evidence of myocardial ischaemia, or with triple vessel disease and impaired left ventricular function, coronary artery bypass graft surgery improves prognosis. ${ }^{105}$

Evidence level IIa

9.9 Patients previously referred for and awaiting CABG surgery who have subsequently developed unstable angina or non-Q wave myocardial infarction have an increased risk of mortality while waiting for surgery. ${ }^{123-}$ 125

Evidence level IV 


\section{Secondary prevention}

10.1 The National Service Framework for Coronary Heart Disease ${ }^{126}$ has advised that patients with diagnosed coronary heart disease should have:

- advice about how to stop smoking, including advice on the use of nicotine replacement therapy;

- information about other modifiable risk factors and personalised advice about how they can be reduced (including advice about physical activity, diet, alcohol consumption, weight and diabetes);

- advice and treatment to maintain blood pressure below 140/85 mm Hg;

- low dose aspirin;

- statins and dietary advice to lower serum cholesterol concentrations EITHER to less than $5 \mathrm{mmol} / \mathrm{l}$ (low density lipoprotein cholesterol to below $3 \mathrm{mmol} / \mathrm{l}$ ) OR by $30 \%$ (whichever is greater);

- angiotensin converting enzyme (ACE) inhibitors for people who also have left ventricular dysfunction;

- $\beta$ blockers for people who also have had a myocardial infarction;

- warfarin or aspirin for people over 60 years old who also have atrial fibrillation;

- meticulous control of blood pressure and glucose in people who also have diabetes.

10.2 These standards are similar to and consistent with those proposed by the joint British recommendations on behalf of the British Cardiac Society, the British Hyperlipidaemia Association, the British Hypertension Society, and the British Diabetic Association $^{127}$; and more recently from The British Hypertension Society. ${ }^{128} 129$

10.3 The National Service Framework for Coronary Heart Disease ${ }^{126}$ has advised that patients who have had an acute cardiac event should be referred for cardiac rehabilitation. We believe that all confirmed acute coronary syndromes are acute cardiac events.

\section{Abbreviations}

AST: aspartate transaminase

CABG: coronary artery bypass graft

CCSC: Canadian Cardiovascular Society classification

CCU: coronary care unit

CK: creatine kinase

CK-MB: creatine kinase MB fraction

$\mathrm{CK}-\mathrm{MB}_{\text {mass }}$ : creatine kinase $\mathrm{MB}$ fraction in mass units

ECG: electrocardiogram

HDU: high dependency unit

LDH: lactate dehydrogenase

MACE: major adverse cardiac events

PTCA: percutaneous transluminal coronary angioplasty

\section{Audit points: proposed dataset}

In patients with a confirmed acute coronary syndrome:

- admitted to CCU/HDU/monitored bed;

- assessed with cardiac troponin measurement (where CK-MB fraction is normal);

- treated with aspirin;

- treated with a $\beta$ blocker (or where contraindicated, a calcium channel blocker with heart rate slowing properties);

- treated with heparin;

- those at high risk treated with a platelet glycoprotein IIb/IIIa inhibitor;

- stabilised patients have their risk assessed with exercise ECG or other stress test (except for those already identified to be at high risk);
- patients identified at high risk referred directly for coronary angiography;

- patients with recurrent or refractory acute coronary syndromes for urgent inpatient coronary angiography;

- waiting times for outpatient coronary angiography in routine and urgent categories;

- delays in inpatient transfer to tertiary centre for coronary angiography for high risk cases;

- total mortality in-hospital and within six months;

- MACE (major adverse cardiac events = cardiac death + non-fatal myocardial infarction + invasive interventions) in-hospital and within six months;

- secondary prevention;

- referral for cardiac rehabilitation.

\section{Appendix}

\subsection{Appendix I}

Strength of evidence and grades of recommendations: The strength of evidence and the recommendations drawn from it were classified according to the definitions used by the Scottish Intercollegiate Guidelines Network, ${ }^{1}$ derived from the US Agency for Health Care Policy and Research. ${ }^{3}$

\section{Statements of evidence}

Ia Evidence obtained from meta-analysis of randomised controlled trials.

Ib Evidence obtained from at least one randomised controlled trial.

IIa Evidence obtained from at least one well designed controlled study without randomisation

IIb Evidence obtained from at least one other type of well designed, quasi-experimental study.

III Evidence obtained from well designed, nonexperimental descriptive studies, such as comparative studies, correlation studies, and case studies.

IV Evidence obtained from expert committee reports or opinions and/or clinical experiences of respected authorities.

\section{Grades of recommendations}

A Requires at least one randomised controlled trial as part of a body of literature of overall good quality and consistency addressing the specific recommendation (evidence levels $\boldsymbol{I} \boldsymbol{a}, \boldsymbol{I} \boldsymbol{b}$ ).

B Requires the availability of well conducted clinical studies but no randomised clinical trials on the topic of recommendation (evidence levels $\boldsymbol{I I} \boldsymbol{a}, \boldsymbol{I I} \boldsymbol{b}, \boldsymbol{I I I})$.

C Requires evidence obtained from expert committee reports or opinions and/or clinical experiences of respected authorities. Indicates an absence of directly applicable clinical studies of good quality (evidence level $\boldsymbol{I} \boldsymbol{V})$.

\subsection{Appendix II}

Patient groups/representatives involved in reviewing guideline:

Marcia Kelson, Research Fellow, College of Health Eve Knight, Liaison Officer, British Cardiac Patients Association

$(\mathbf{M})$, meta-analysis; $(\mathbf{R})$, randomised controlled trial; $(\mathbf{S})$, systematic review 1 Scottish Intercollegiate Guidelines Network (SIGN). http://www.sign.ac.uk 2 Yusuf S, Flather M, Pogue J, et al. Organisation to Assess Strategies for Ischaemic Syndromes (OASIS) Registry Investigators. Variations between countries in invasive cardiac procedures and outcomes in patients with suspected unstable angina or myocardial infarction without initial ST

3 Braunwald E, Mark DB, Jones RH, et al. Unstable angina: diagnosis and management. Clinical Practice Guideline No 10. Rockville, Maryland: Agency for Health Care Policy and Research, National Heart, Lung and Blood 
Institute, Public Health Service, US Department of Health and Human Services, AHCPR Publication number 94-0602, March 1994. http:// www.ahcpr.gov/clinic/ Accessed at: http://text.nlm.nih.gov/tempfiles/is/ tempD136187.htm

4 Shah PK. New insights into the pathogenesis and prevention of acute coronary syndromes. Am f Cardiol 1997;79(12B):17-23.

5 Fuster V, Badimon L, Cohen M, et al. Insights into the pathogenesis of acute ischemic syndromes. Circulation 1988;77:1213-20.

6 Kristensen SD, Rayn HB, Falk E. Insights into the pathophysiology of unstable coronary artery disease. Am f Cardiol 1997;80(5A):5E-9E.

7 Davies MJ, Thomas AC. Plaque fissuring: the cause of acute myocardial infarction, sudden death and unstable angina. Br Heart $\mathcal{f}$ 1985;53:363-73.

8 Anzai T, Yoshikawa T, Asakura Y, et al. Preinfarction angina as a major preAnzai T, Yoshikawa T, Asakura Y, et al. Preinfarction angina as a major pre-
dictor of left ventricular function and long-term prognosis after a first Q dictor of left ventricular function and long-term prognosis after
wave myocardial infarction. $\mathcal{F}$ Am Coll Cardiol 1995;26:319-27.

9 The Global Use of Strategies to Open Occluded Coronary Arteries (GUSTO) IIb investigators. A comparison of recombinant hirudin with heparin for the treatment of acute coronary syndromes. $N$ Engl f Med 1996;335:775-82. (R)

10 TIMI IIIB Investigators. Effects of tissue plasminogen activator and a comparison of early invasive and conservative strategies in unstable angina and non-Q-wave myocardial infarction. Results of the TIMI If

11 Fragmin during Instability in Coronary Artery Disease (FRISC) Study Group. Low-molecular-weight heparin during instability in coronary artery Group. Low-molecular-weight heparin
disease. Lancet 1996;347:561-8. (R)

12 Klein W, Buchwald A, Hillis SE, et al. Comparison of low-molecular-weight heparin with unfractionated heparin acutely and with placebo for 6 weeks in the management of unstable coronary artery disease. Fragmin in unstable coronary artery disease study (FRIC). Circulation 1997;96:61-8. (R)
Braunwald E. Unstable angina. A classification. Circulation 1989;80:410-4

14 Patel DJ, Holdright DR, Knight CJ, et al. Early continuous ST segment monitoring in unstable angina: prognostic value additional to the clinical

15 Patel DJ, Knight CJ, Holdright DR, et al. Long-term prognosis in unstable angina. The importance of early risk stratification using continuous ST segment monitoring. Eur Heart f 1998;19:240-9.

16 Hamm CW, Ravkilde J, Gerhardt W, et al. The prognostic value of serum troponin T in unstable angina. N Egl f Med 1992;327:262-4.

17 Stubbs P, Collinson P, Moseley D, et al. Prospective study of the role of cardiac troponin $T$ in patients admitted with unstable angina. BMF 1996;313: $262-4$.

18 Solymoss BC, Bourassa MG, Wesolowska E, et al. The role of cardiac troponin $\mathrm{T}$ and other new biochemical markers in evaluation and risk stratification of patients with acute chest pain syndromes. Clin Cardiol 1997;20:934-42.

19 Luscher MS, Thygesen K, Ravkilde J, et al for the TRIM Study Group. Applicability of cardiac troponin $\mathrm{T}$ and I for early risk stratification in unstable coronary disease. Circulation 1997;96:2578-85.

20 Hamm CW, Goldmann BU, Heeschen C, et al. Emergency room triage of patients with acute chest pain by means of rapid testing for troponin $\mathrm{T}$ or I. patients with acute chest pain by 1 .
N Engl F Med 1997;337:1648-53.

21 Ohman EM, Armstrong PW, Christenson RH, et al, for the GUSTO-IIa Investigators. Cardiac troponin T levels for risk stratification in acute myocardial ischemia. N Engl $\mathfrak{f}$ Med 1996;335:1333-41.

22 Antman EM, Tanasijevic MJ, Thompson B, et al. Cardiac-specific troponin levels to predict the risk of mortality in patients with acute coronary syndromes. N Engl f Med 1996;335:1342-9.

23 Antman EM, Cohen M, Bernink PJ, et al. The TIMI risk score for unstable angina/non-ST elevation MI: a method for prognostication and therapeutic decision making. JAMA 2000;284:835-42.

24 Moreno R, Lopez de Sa E, Lopez-Sendon J-L, et al. Prognosis of medically stabilized unstable angina pectoris with a negative exercise test. Am f Cardiol 1998;82:662-5.

25 Betriu A, Heras $M$, Cohen $M$, et al. Unstable angina outcomes according to clinical presentation. 7 Am Coll Cardiol 1992;19:1659-63.

26 Nyman I, Areskog M, Areskog NH, et al. Very early risk stratification by electrocardiogram at rest in men with suspected unstable coronary heart disease. The RISC study group. F Intern Med 1993;234:293-301.

27 Anderson K, Eriksson P, Dellborg M. Non-invasive risk stratification within 48 hours of hospital admission in patients with unstable coronary artery disease. Eur Heart f 1997;18:780-8.

28 Holmvang L, Andersen K, Delloborg M, et al. Relative contributions of a single admission 12-lead electrocardiogram and early 24-hour continuous electrocardiograph monitoring for early risk stratification in patients with unstable coronary artery disease. Am F Cardiol 1999;83:667-74.

29 Savonitto S, Ardissino D, Granger CB, et al. Prognostic value of the admission electrocardiogram in acute coronary syndromes. FAMA 1999;281: 707-13.

30 Liuzzo G, Biasucci LM, Gallimore JR, et al. The prognostic value of C-reactive protein and serum amyloid A protein in severe unstable angina. N Engl F Med 1994;331:417-24.

31 Rebuzzi AG, Quaranta G, Liuzzo G, et al. Incremental prognostic value of serum levels of troponin $\mathrm{T}$ and $\mathrm{C}$-reactive protein on admission in patients serum levels of troponin T and C-reactive protein on admiss
with unstable angina pectoris. Am f Cardiol 1998;82:715-9.

32 Olatidoye AG, Wu AHB, Feng Y-J, et al. Prognostic role of troponin T versus troponin I in unstable angina perctoris for cardiac events with meta-analysis comparing published studies. Am f Cardiol 1998;81:140510. (M)

33 Hillis GS, Zhao, Taggart P, Dalsey WC, et al. Utility of cardiac troponin I, creatine kinase- $M \mathrm{~B}_{\text {mass }}$, myosin light chain 1 , and myoglobin in the early
in-hospital triage of "high risk" patients with chest pain. Heart 1999;82:614-20.

34 Farkouh ME, Smars PA, Reeder GS, et al. A clinical trial of a chest pain observation unit for patients with unstable angina. N Engl f Med 1998;339: 1882-8. (R)

35 Roberts RR, Zalenski RJ, Mensah EK, et al. Costs of an emergency department-based diagnostic protocol vs hospitalisation in patiens with chest pain. A randomised controlled trial. $¥ A M A$ 1997;278:1670-6. (R)

36 Gomez MA, Anderson JL, Karagounis LA, et al. An emergency department-based protocol for rapidly ruling out myocardial ischemia reduces hospital time and expense: results of a randomized study
(ROMIO). F Am Coll Cardiol 1996;28:25-33. (R)
37 Gaspoz J, Lee TH, Weinstein MC, et al. Cost-effectiveness of a new shortstay unit to "rule out" acute myocardial infarction in low risk patients. $\mathcal{F} \mathrm{Am}$ stay unit to "rule out" acute my
Coll Cardiol 1994;24:1249-59.

38 Kerns JR, Shaub TF, Fontanarosa PB. Emergency cardiac stress testing in the evaluation of emergency department patients with atypical chest pain. Ann Emerg Med 1993;22:794-8.

39 Newby DE, Fox KAA, Flint LL, et al. A 'same day' direct-access chest pain clinic: improved management and reduced hospitalization. QfM 1998;91: 333-7

40 Davie AP, Caesar D, Caruana L, et al. Outcome from a rapid-assessment chest pain clinic. $Q \mathscr{7} M$ 1998;91:339-43.

41 Goodacre SW. Should we establish chest pain observation units in the UK? A systematic review $2000 ; 17: 1-6 .(\mathbf{S})$

42 Pavin D, Delonca J, Siegenthlaer M, et al. Long-term (10 years) prognostic value of a normal thallium-201 myocardial exercise scintigraphy in patients with coronary artery disease documented by angiography. Eur Heart $\mathcal{f}$ with coronary arte.

43 Heller GV, Stowers SA, Hendel RC, et al. Clinical value of acute rest technetium-99m tetrofosmin tomographic myocardial perfusion imaging in patients with acute chest pain and nondiagnostic electrocardiograms. $\mathcal{F} \mathrm{Am}$ Coll Cardiol 1998;31:1011-7.

44 Lindahl B, Andren B, Ohlsson J, et al and the FRISC Study Group. Risk stratification in unstable coronary artery disease. Additive value of troponin
$\mathrm{T}$ determinations and predischarge exercise tests. Eur Heart $\mathcal{F}$ 1997;18: $\mathrm{T}$ determ
$762-70$

45 Bodenheimer MM, Wackers FJ, Schwartz RG, et al. Prognostic significance of a fixed thallium defect one to six months after onset of acute myocardial infarction or unstable angina. Multicentre myocardial ischemia research group. Am F Cardiol 1994;74:1 196-200.

46 Miller DD, Stratmann HG, Shaw L, et al. Dipyridamole technetium 99m sestamibi myocardial tomography as an independent predictor of cardiac event-free survival after ischaemic events. $\mathcal{F}$ Nucl Cardiol 1994;1:72-82.

47 Stratmann HG, Younis LT, Wittry MD, et al. Exercise technetium-99m myocardial tomography for the risk stratification of men with medically myocardial tomography for the risk stratification of men with

48 Stratmann HG, Tamesis BR, Younis LT, et al. Prognostic value of predischarge dipyridamole technetium sestamibi myocardial tomography in medically treated patients with unstable angina. Am Heart $\mathcal{f}$ 1995;130:734-40.

49 Barakat K, Kennon S, Wilkinson P, et al. Selection bias in the management of unstable angina. F R Coll Physic 2000;34:179-84

50 van Miltenburg van Zijl AJ, Simoons ML, Veerhoek RJ, et al. Incidence and follow-up of Braunwald subgroups in unstable angina pectoris. $7 \mathrm{Am}$ Coll Cardiol 1995;25:1286-92.

51 Lin SS, Lauer MS, Marwick TH. Risk stratification of patients with medically treated unstable angina using exercise echocardiography. $\mathrm{Am} \mathcal{F}$ Cardiol 1998;82:720-4.

52 Scanlon PJ, Faxon DP, Audet AM, et al. ACC/AHA guidelines for coronary angiography: a report of the American College of Cardiology/American Heart Association task force on practice guidelines (committee on coronary angiography). f Am Coll Cardiol 1999;33:1756-824. http://

53 Antiplatelet Trialists' Collaboration. Collaborative overview of randomised trials of antiplatelet therapy - I: prevention of death, myocardial infarction, and stroke by prolonged antiplatelet therapy in various categories of patients. BMF 1994;308:81-106. (M) (S)

54 Theroux P, Waters D, Qiu S, et al. Aspirin versus heparin to prevent myocardial infarction during the acute phase of unstable angina. Circulation 1993; 88:2045-8. (R)

55 Theroux P, Ouimet H, McCans J, et al. Aspirin, heparin, or both to treat acute unstable angina. N Engl f Med 1988;319:1105-11. (R)

56 Oler A, Whooley MA, Oler J, et al. Adding heparin to aspirin reduces the incidence of myocardial infarction and death in patients with unstable angina. A meta-analysis. $\mathcal{F A M A} 1996 ; 276: 811-5$. (M) (S)

57 Cohen M, Demers C, Gurfinkel EP, et al for the Efficacy, and Safety of Subcutaneous Enoxaparin in Non-Q-wave Coronary Events (ESSENCE) cutaneous Enoxaparin in Non-Q-wave Coronary Events (ESSENCE) Study Group. A comparison of low-molecular weight heparin with unfrac-
tionated heparin for unstable coronary artery disease. N Engl f Med 1997; 337:447-52. (R)

58 Antman EM, McCabe CH, Gurfinkel EP, et al. Enoxaparin prevents death and cardiac ischemic events in unstable angina/non-Q-wave myocardial infarction. Results of the Thrombolysis in myocardial infarction (TIMI) 11 b trial. Circulation 1999;100:1593-601. (R)

59 Antman EM, Cohen M, Radley D, et al. Assessment of the treatment effect of enoxaparin for unstable angina/non-Q-wave myocardial infarction. TIMI 11b-ESSENCE meta-analysis. Circulation 1999;100:1602-8. (M)

60 FRAXIS Investigators. Comparison of two treatment durations (6 days and 14 days) of a low molecular weight heparin with a 6-day treatment of unfractionated heparin in the initial management of unstable angina or drome). Eur Heart $\mathcal{f} 1999 ; 20: 1553-62$. (R)

61 FRISC II Investigators. Long-term low-molecular-weight heparin in unstable coronary artery disease. FRISC II prospective randomised multicentre ble coronary artery disease. FRISC
study. Lancet 1999;354:701-7. (R)

62 Eikelboom JW, Anand SS, Malmberg K, et al. Unfractionated heparin and low-molecular-weight heparin in acute coronary syndrome without ST elevation: a meta-analysis. Lancet 2000;355:1936-42. (S) (M)

63 Kong DF, Califf RM, Miller DP, et al. Clinical outcomes of therapeutic agents that block the platelet glycoprotein IIb/IIIa integrin in ischemic heart disease. Circulation 1998;98:2829-35. (S)

64 The EPILOG Investigators. Platelet glycoprotein IIb/IIIa receptor blockade and low-dose heparin during percutaneous coronary revascularisation. $N$ Engl f Med 1997;336:1689-96. (R)

65 The EPIC Investigators. Use of a monoclonal antibody directed against the platelet glycoprotein IIb/IIa receptor in high risk coronary angioplasty. $N$ Engl F Med 1994;330:956-61. (R)

66 The CAPTURE Investigators. Randomised placebo-controlled trial of abciximab before and during coronary intervention in refractory unstable angina: the CAPTURE study. Lancet 1997;349:1429-35. (R)

67 Heeschen C, Hamm CW, Goldmann B, et al for the PRISM investigators. Troponin concentrations for stratification of patients with acute coronary syndromes in relation to therapeutic efficacy of tirofiban. Lancet 1999;354: 1757-62. (R) 
68 Hamm CW, Heeschen C, Goldmann B, et al for the CAPTURE Study Investigators. Benefit of abciximab in patients with refractory unstable
angina in relation to serum troponin $\mathrm{T}$ levels. $N$ Engl $\underset{f}{\text { Med }}$ angina in relation to
$1999 ; 340: 1623-9 .(\mathbf{R})$

69 Boersma E, Akkerhuis KM, Theroux P, et al. Platelet glycoprotein IIb/IIIa receptor inhibition in non-ST-elevation acute coronary syndromes: early benefit during medical treatment only, with additional protection during percutaneous coronary intervention. Circulation 1999;100:2045-8. (M)
Adgey AAJ. An overview of the results of clinical trials with glycoprotein IIb/ III inhibitors. Eur Heart f 1998;19(suppl D):D10-21. (S)

71 Fox KAA. Comparing trials of glycoprotein IIb/IIIa receptor antagonists. Eur Heart f 1999;20(suppl R):R10-17. (S)

72 ISIS-2 (Second International Study of Infarct Survival) Collaborative Group. Randomised trial of intravenous streptokinase, oral aspirin, both or neither among 17,187 cases of suspe

73 Fibrinolytic Therapy Trialists' Collaborative Group. Indications for fibrinolytic therapy in suspected acute myocardial infarction: collaborative overview of early mortality and major morbidity results from all randomised trials of more than 1000 patients. Lancet 1994;343:311-22. (M) (S)

74 Lee HS, Cross SJ, Rawles JM, et al. Patients with suspected myocardial infarction who present with ST depression. Lancet 1993;342:1204-7. (R) 5 Borzak S, Verter J, Bajwa HS, et al. Thrombolytic therapy for unstable angina. Clin Cardiol 1993;16:637-41. (R)

76 Roubin GS, Harris PJ, Eckhardt I, et al. Intravenous nitroglycerin in refractory unstable angina pectoris. Aust NZ F Med 1982;12:598-602.

77 DePace NL, Herling IH, Kotler MN, et al. Intravenous nitroglycerin for rest angina: potential pathophysiologic mechanisms of action. Arch Intern Med 1982;142:1806-9.

78 Caplan K, Davison R, Parker M, et al. Intravenous nitroglycerin for the treatment of angina at rest not responsive to standard nitrate therapy. $A m \mathcal{F}$ Cardiol 1983;51:694-8.

79 Page A, Gateau P, Ohayon J, et al. Intravenous nitroglycerin in unstable angina. In: Lechtlen PR, Engel H, eds. Nitrates III: cardiovascular effects. Berlin: Springer-Verlag, 1981: 371-6.

80 Mikolich JR, Nicoloff NB, Robinson RH, et al. Relief of refractory angina with continuous intravenous infusion of nitroglycerin. Chest 1980;77:3759 .

81 Squire A, Cantor R, Packer M. Limitations of continuous intravenous nitroglycerin in patients with refractory angina at rest. Circulation 1982;66(suppl II):II-120.

82 Heinsimer JA, Curfman GD, Fung HL, et al. Intravenous nitroglycerin for spontaneous angina: a short term, prospective, randomised trial [abstract]. Circulation 1981;64:1V-10.

83 Curfman GD, Heinsimer JA, Lozner EC, et al. Intravenous nitroglycerin in the treatment of spontaneous angina pectoris: a prospective randomised trial. Circulation 1983;67:276-82. (R)

84 Dellborg M, Gustafsson G, Swedberg K. Buccal versus intravenous nitroglycerin in unstable angina pectoris. Eur f Clin Pharmacol 1991;41:59. (R)

85 Muller JE, Turi ZG, Pearle DL, et al. Nifedipine and conventional therapy for unstable angina pectoris: a randomised, double-blind comparison. Circulation 1984;69:728-39. (R)

86 Holland Interuniversity Nifedipine/Metoprolol Trial (HINT) Research Group. Early treatment of unstable angina in the coronary care unit: a randomised, double-blind, placebo controlled comparison of recurrent ischemia in patient treated with nifedipine or metoprolol or both. Br Heart ischemia in patient tre

87 Gottlieb SO, Weisfeldt $\mathrm{M}$, Ouyang $\mathrm{P}$, et al. Effect of the addition of propranolol to therapy with nifedipine for unstable angina pectoris. A randomised, double-blind, placebo controlled trial. Circulation 1986;73:331-7. (R)

88 Andre-Fouet X, Usdin JP, Gayet CHG, et al. Comparison of short-term efficacy of diltiazem and propranolol in unstable angina at rest-randomised trial in 70 patients. Eur Heart $\mathcal{F} 1983 ; 4: 69-98$. (R)

89 Gerstenblith G, Ouyang P, Achuff SC, et al. Nifedipine in unstable angina: a double-blind randomised trial. N Engl f Med 1982;306:885-9. (R)

90 Patel DJ, Purcell HJ, Fox KM. Cardioprotection by opening of the KATP channel in unstable angina. Is this a clinical manifestation of myocardial preconditioning? Results of a randomised study with nicorandil. Eur Heart $\mathscr{f} 1999 ; 20: 51-7$. (R)

91 Yusuf S, Wittes J, Friedman L. Overview of results of randomised clinical trials in heart disease. II. Unstable angina, heart failure, primary prevention with aspirin, and risk factor modification. JAMA 1988;260:2259-63. (M)

92 (S)

Gibson RS, Boden WE, Theroux P, et al. Diltiazem and reinfarction in patients with non- $\mathrm{Q}$ wave myocardial infarction: Results of a double-blind, randomised, multicenter trial. N Engl f Med 1986;315:423-9. (R)

93 The Multicenter Diltiazem Postinfarction Trial Research Group. The effect of diltiazem on mortality and reinfarction after myocardial infarction. $N$ Engl F Med 1988;319:385-92. (R)

94 Goldstein RE, Bocuzzi SJ, Cruess D, et al. Diltiazem increases late-onset congestive heart failure in post infarction patients with early reduction in ejection fraction. Circulation 1991;83:52-60

95 Rengo F, Carbonin P, Pahior M, et al. A controlled trial of verapamil in patients after acute myocardial infarction: results of the calcium antagonist reinfarction Italian study (CRIS). Am 7 Cardiol 1996;77:421-22. (R)

96 The Danish Study Group on Verapamil in Myocardial Infarction. Effect of verapamil on mortality and major events after acute myocardial infarction (the Danish verapamil infarction trial II-DAVIT II). Am $\mathcal{f}$ Cardiol 1990;66:779-85. (R)

97 Eagle KA, Guyton RA, Davidoff R, et al. ACC/AHA guidelines for coronary artery bypass graft surgery: executive summary and recommendations: a report of the American College of Cardiology/American Heart Association task force on practice guidelines (committee to revise the 1991 guidelines for coronary artery bypass graft surgery). Circulation 1999;100:1464-80. http://www.americanheart.org/scientific/statements (71-0174). Accessed http://www.americanheart.org/scientific/statements (71-0174)
at: http://circ.ahajournals.org/cgi/content/full/100/13/1464
98 Sim I, Gupta M, McDonald K, et al. A meta-analysis of randomized trials comparing coronary artery bypass grafting with percutaneous transluminal coornary angioplasty in multivessel coronary artery disease. Am $\mathrm{f}$ Cardiol 1995;76:1025-9. (M)

99 Pocock SJ, Henderson RA, Rickards AF, et al. Meta-analysis of randomised trials comparing coronary angioplasty with bypass surgery. Lancet 1995;346:1184-9. (M)

100 Luchi RJ, Scott SM, Deupree RH. Comparison of medical and surgical treatment for unstable angina pectoris. Results of a Veterans Administration co-operative study. N Engl F Med 1987;316:977-84. (R)

101 Pairisi JS, Khuri S, Deupree RH, et al. Medical compared with surgical management of unstable angina. 5 year mortality and morbidity in the Veterans Administration study. Circulation 1989;80:1176-89. (R)

102 Scott SM, Luchi RJ, Deupree RH. Veterans Administration co-operative study for treatment of patients with unstable angina. Results in patients with abnormal left ventricular function. Circulation 1988;78:I113-21. (R)

103 Sharma GV, Deupree RH, Khuri SF, et al. Coronary artery surgery improves survival in high-risk unstable angina. Results of a Veterans Administration co-operative study with an 8 year follow-up. Veterans Administration co-operative study group. Circulation 1991;84:II1260-7.

104 Russell RO, Moraski RE, Kouchoukos N, et al. Unstable angina pectoris: national co-operative study group to compare surgical and medical therapy. Am $\mathcal{f}$ Cardiol 1978;42:839-48.

105 McCormick JR, Schick EC, McCabe CH, et al. Determinants of operative mortality and long term survival in patients with unstable angina. $\mathcal{F}$ Thorac Cardiovasc Surg 1985;89:683-8.

106 Anderson HV, Cannon CP, Stone PH, et al. One year results of the thrombolysis in myocardial infarction (TIMI) IIIb trial: a randomised comparison of tissue-type plasminogen activator versus placebo and early invasive versus early conservative management strategies in unstable angina and non-Q-wave myocardial infarction. F Am Coll Cardiol 1995;26:164350. (R)

107 Boden WE, O'Rourke RA, Crawford MH, et al. Outcomes in patients with acute non-Q-wave myocardial infarction randomly assigned to an invasive as compared with a conservative management strategy. Veterans Affairs non-Q-wave infarction strategies in hospital (VANQUISH) trial investigators. N Engl f Med 1998;338:1785-92. (R)

108 McCullough PA, O'Neill WW, Graham M, et al. A prospective randomised trial of triage angiography in acute coronary syndromes ineligible for thrombolytic therapy. Results of the medicine versus angiography in thrombolytic exclusion (MATE) trial. f Am Coll Cardiol 1998;32:596-605. (R)

109 Mehta S, Yusuf S, Hunt D, et al. Invasive versus conservative management of unstable angina and non-Q-wave myocardial infarction: a meta-analysis. Circulation 1999;100:I-775. (M)

110 FRISC II Investigators. Invasive compared with non-invasive treatment in unstable coronary artery disease: FRISC II prospective randomised multicentre study. Lancet 1999;354:708-15. (R)

111 Cho L, Marso SP, Bhatt DL, et al. An early invasive strategy is associated with decreased mortality: GUSTO IIb trial. Circulation 1999;100:I-359.

112 Goy JJ. Contemporary approach to management of unstable angina [editorial] Lancet 1999;354:694-5.

113 Markiewicz W. Management of unstable coronary artery disease [letter]. Lancet 2000;355:572.

114 Keavney B, Haider YM, McCance AJ, et al. Normal coronary angiograms: financial victory from the brink of clinical defeat? Heart 1996;75:623-5.

115 Wynne-Jones K, Jackson M, Grotte G, et al. Limitations of the Parsonnet score for measuring risk stratified mortality in the north west of England. Heart 2000;84:71-8

116 http://www.sts.org/ January 1999

117 Tu JV, Jagal SB, Naylor D. Multi-centre validation of a risk index for mortality, intensive care unit stay, and overall hospital length of stay after cardiac surgery. Circulation 1995;91:677-84.

118 Magovern JA, Sakert T, Magovern GJ, et al. A model that predicts morbidity and mortality after coronary artery bypass graft surgery. $7 \mathrm{Am}$ Coll Cardiol 1996;28:1147-53.

119 Parsonnet V, Dean D, Bernstein AD. A method of uniform stratification of risk for evaluating the results of surgery in acquired adult heart disease. Circulation 1989;79(suppl I):I3-12.

120 Tu JV, Sykora K, Naylor CD. Assessing the outcome of coronary artery bypass graft surgery: how many risk factors are enough. $\mathcal{f} \mathrm{Am}$ Coll Cardiol 1997;30:1317-23.

121 Edwards FH, Clark RE, Schwartz M. Coronary artery bypass grafting: the Society of Thoracic Surgeons National Database Experience. Ann Thorac Surg 1994;57:12-9.

122 Grover FL, Hammermeister KE, Burchfiel C. Initial report of the Veterans Administration preoperative risk assessment study for cardiac surgery. Ann Thorac Surg 1990;50:12-28.

123 Bridgewater B. Death on the waiting list for coronary artery surgery. Heart 1999;81:564.

124 Seddon ME, French JK, Amos DJ, et al. Waiting time and prioritisation for coronary artery bypass surgery in New Zealand. Heart 1999;81:586-92.

125 Suttorp MJ, Kingma JH, Vos J, et al. Determinants for early mortality in patients awaiting coronary artery bypass graft surgery: a case control study. Eur Heart $\mathcal{F}$ 1992;13:238-42.

126 National Service Framework for Coronary Heart Disease, 2000. http://www.doh.gov.uk/nsf/coronary.htm

127 Wood D, Durrington P, Poulter N, et al, on behalf of the Societies. Joint British recommendations on prevention of coronary heart disease in clinical practice. Heart 1998;80(suppl 2):S1-29.

128 Ramsay LE, Williams B, Johnston DG, et al. British Hypertension Society guidelines for hypertension management 1999: a summary. BMF 1999;319:630-5.

129 Ramsay LE, Williams B, Johnston DG, et al. Guidelines for management of hypertension: Report of the Third Working Party of the British Hypertension Society. $\mathcal{F}$ Human Hypertens 1999;13:569-92. 